\title{
What's new in the prevention of healthcare-associated infections using chlorhexidine gluconate-impregnated washcloths
}

\author{
Sandrine Dray, Jean-Marie Forel and Laurent Papazian *
}

๑) 2018 Springer-Verlag GmbH Germany, part of Springer Nature and ESICM

Critically ill patients hospitalized in intensive care units (ICUs) are at high risk for health care-associated infections (HAIs) in relation to their underlying conditions, comorbidities, impaired host defences, and the placement of invasive devices (endotracheal tubes, bladder catheters, and intravascular devices including catheters). These HAIs include surgical site infections, central line-associated bloodstream infections, catheterassociated urinary tract infections, ventilator-associated pneumonias (VAPs), and bloodstream infections. HAIs are strongly associated with prolonged length of stay, increased mortality and increased costs. In addition, the number of infections related to multidrug resistant organisms (MDROs) is increasing and is associated with a limited number of effective antimicrobial drugs. Many of these organisms such as methicillin-resistant Staphylococcus aureus (MRSA) and carbapenem-resistant Enterobacteriaceae colonize the skin of hospitalized patients.

Several strategies are proposed for preventing HAIs, including adequate nursing staff, hand hygiene compliance, aseptic techniques for the insertion of a catheter, avoidance of unnecessary use of indwelling devices, and contact isolation precautions for patients colonized/ infected with MDRO. One of the newer strategies of growing interest for ICU patients is skin disinfection with chlorhexidine. Indeed, the skin of patients is considered to be a major reservoir for pathogens associated with HAIs, and interventions aiming to reduce bacterial burden and the subsequent risk of infection are of potential interest. Chlorhexidine gluconate (CHG) is a widely used antiseptic agent with broad antimicrobial action against Gram-positive and Gram-negative organisms, facultative anaerobes, aerobes, and yeasts. It has also been shown that the use of CHG-impregnated wipes is able to reduce cross-transmission and colonization in the ICU in an endemic situation resulting from multidrug-resistant Enterobacteriaceae [1]. However, it has been clearly established that the activity of CHG on MDR Gram-negative is dependent on the skin concentration [2]. CHG has been successfully assessed as an effective skin antiseptic since the early 1970s. It exhibits a prolonged residual effect and is the agent of choice for skin disinfection in ICU patients before catheter insertion. This agent may also lower the risk of horizontal transmission of bacteria to other patients. Whole-body bathing with $\mathrm{CHG}$ is one of the approaches intended to reduce bacterial density on the skin of patients instead of, or after, normal soap-and-water bathing. A CHG body bath or skin cleansing is used in a variety of settings including the haematology/oncology units or prior to high-risk surgical procedures. While CHG is usually used in basic hygienic care as a liquid bathing agent, it can also be applied directly as a solution by clean wipes or as an ingredient in soaps and gels. It is now available as pre-packaged CHG-impregnated washcloths. This is a unique no-rinse system involving impregnated $\mathrm{CHG}$ in a 
polyester disposable preparation cloth, which has been shown to deliver CHG (500 mg) more effectively, leading to a greater and rapid reduction in bacterial load on the skin [3]. Indeed, in healthy volunteers, cleansing with $2 \%$ CHG-impregnated cloths yielded higher residual CHG concentrations and lower bacterial densities than cleansing with a 4\% CHG liquid applied with either of two different cloth types and followed by rinsing [4]. Application of CHG on the patient's body without rinsing, by washcloths impregnated or saturated with CHG, may have a different impact due to the residual effect compared with the application of CHG that involves a post-application rinse.

The richness and diversity of bacteria found on the skin of ICU patients are modified by the use of pre-packaged CHG-impregnated washcloths. Indeed, for patients at day seven of ICU hospitalization, daily CHG bathing is associated with a reduction in both skin bacterial richness and diversity compared with control patients for whom water and soap were used [5]. Interestingly, in this latter report, this modification was mainly due to a significant reduction in Gram-negative bacteria colonization [5]. This efficacy regarding Gram-negative bacteria was also suggested by a clinical study done in a medical ICU that showed that the use of pre-packaged CHG-impregnated washcloths was associated with a drop in the incidence rate of HAI caused by Gram-negative bacteria [6]. This is a key issue because major randomised controlled trials [7-11] have been done in order to decrease the incidence of MRSA (Table 1). In these latter studies [7-11], no beneficial effect has been reported regarding Gram-negative bacteraemia (Table 1). This is mainly due to the very low incidence of such infections observed in the participating ICUs, which is probably related to the short duration of stay [7-11]. It was reported that protection against primary bloodstream infection by pre-packaged CHG-impregnated washcloths was apparent after 5 or more days in one study [7] and increased with time in another one [8]. Indeed, among patients who were in the ICU for more than 7 days, the relative risk of a primary bloodstream infection was 0.69 (for patients bathed with chlorhexidine compared with those bathed with non-antimicrobial washcloths) and reached 0.51 among patients who were in the unit for more than 14 days. It is, therefore, crucial now to carefully evaluate the use of pre-packaged CHG-impregnated washcloths in patients at high risk of Gram-negative infection from remaining in the ICU for at least 1 week. Indeed, in a recent report [12] investigating 571 episodes of ICU-acquired bloodstream infection, more than $40 \%$ were related to Gramnegative bacteria.

Regarding the antibacterial spectrum of CHG, we have to be cautious regarding the activity against certain

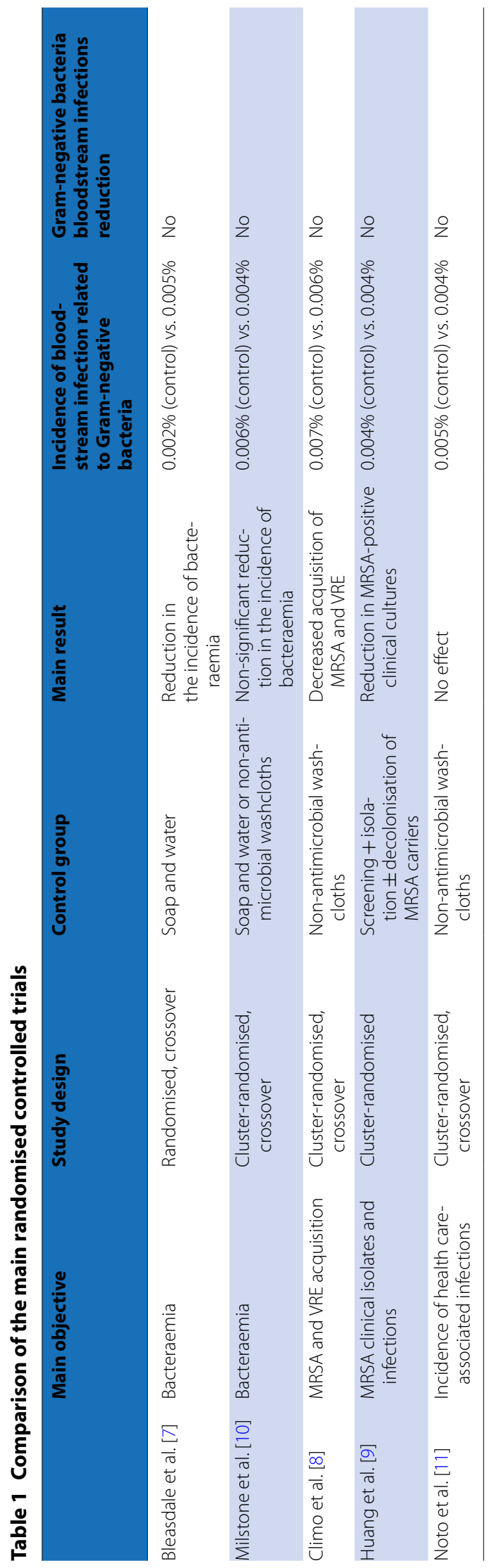


Enterobacteriaceae such as Escherichia coli. A recent study done in mechanically ventilated patients showed that about one quarter of the 260 strains responsible for VAP were resistant to CHG [13]. The increasing use of chlorhexidine has generated concern regarding the possible emergence of CHG resistance. Low-level chlorhexidine resistance (tolerance) is well described in Staphylococci and is due to the activity of multidrugefflux pumps mediated by genes qacA and qacB. However, a recent single-center study covering 7.5 years was unable to show any significant modification in the resistance profile of $\mathrm{S}$. aureus isolates related to extensive use of CHG [14]. However, we have to be cautious with this risk and include in further studies the long-term evaluation of CHG resistance especially regarding Gramnegative infections. Moreover, standardized methods of resistance testing and interpretation need to be established.

Regarding skin toxicity, it has been reported that receiving daily chlorhexidine bathing was well tolerated in patients treated with remission induction chemotherapy or autologous or allogeneic stem cell transplantation; these patients did not develop skin lesions even when treated with IV cytarabine [15].

Finally, one major aspect is the economic burden of a strategy based on a widespread use of pre-packaged CHG-impregnated washcloths. This economical parameter should be balanced with the easy adoption and sustainability of use by nurses and the improved comfort reported by patients. Finally, other antiseptic agents could be used. One major issue is to define the targeted population, probably patients at risk of prolonged ICU stay.

To summarize, there is a need for trials exploring the safety (resistance, toxicity), the cost-efficiency, and the impact of the systematic of use pre-packaged CHGimpregnated washcloths in patients at high-risk for Gram-negative infections related to a prolonged stay in the ICU.

\section{Compliance with ethical standards}

Conflicts of interest

No conflict of interests.

Received: 17 July 2018 Accepted: 21 August 2018

Published online: 26 November 2018

\section{References}

1. Ruiz J, Ramirez P, Villarreal E, Gordon M, Saez I, Rodriguez A, Castaneda MJ, Castellanos-Ortega A (2017) Daily bathing strategies and cross-transmission of multidrug-resistant organisms: impact of chlorhexidine-impregnated wipes in a multidrug-resistant gram-negative bacteria endemic intensive care unit. Am J Infect Control 45:1069-1073

2. Lin MY, Lolans K, Blom DW, Lyles RD, Weiner S, Poluru KB, Moore N, Hines DW, Weinstein RA, Hayden MK, Centers for Disease C, Prevention Epicenter P (2014) The effectiveness of routine daily chlorhexidine gluconate bathing in reducing klebsiella pneumoniae carbapenemase-producing Enterobacteriaceae skin burden among long-term acute care hospital patients. Infect Control Hosp Epidemiol 35:440-442

3. Edmiston CE Jr, Seabrook GR, Johnson CP, Paulson DS, Beausoleil CM (2007) Comparative of a new and innovative $2 \%$ chlorhexidine gluconate-impregnated cloth with $4 \%$ chlorhexidine gluconate as topical antiseptic for preparation of the skin prior to surgery. Am J Infect Control 35:89-96

4. Rhee Y, Palmer LJ, Okamoto K, Gemunden S, Hammouda K, Kemble SK, Lin MY, Lolans K, Fogg L, Guanaga D, Yokoe DS, Weinstein RA, Frendl G, Hayden MK, Centers for Disease C, Prevention Epicenter P (2018) Differential effects of chlorhexidine skin cleansing methods on residual chlorhexidine skin concentrations and bacterial recovery. Infect Control Hosp Epidemiol 39:405-411

5. Cassir N, Papazian L, Fournier PE, Raoult D, La Scola B (2015) Insights into bacterial colonization of intensive care patients'skin: the effect of chlorhexidine daily bathing. Eur J Clin Microbiol Infect Dis 34:999-1004

6. Cassir N, Thomas G, Hraiech S, Brunet J, Fournier PE, La Scola B, Papazian $L$ (2015) Chlorhexidine daily bathing: impact on health care-associated infections caused by gram-negative bacteria. Am J Infect Control 43:640-643

7. Bleasdale SC, Trick WE, Gonzalez IM, Lyles RD, Hayden MK, Weinstein RA (2007) Effectiveness of chlorhexidine bathing to reduce catheter-associated bloodstream infections in medical intensive care unit patients. Arch Intern Med 167:2073-2079

8. Climo MW, Yokoe DS, Warren DK, Perl TM, Bolon M, Herwaldt LA, Weinstein RA, Sepkowitz KA, Jernigan JA, Sanogo K, Wong ES (2013) Effect of daily chlorhexidine bathing on hospital-acquired infection. N Engl J Med 368:533-542

9. Huang SS, Septimus E, Kleinman K, Moody J, Hickok J, Avery TR, Lankiewicz J, Gombosev A, Terpstra L, Hartford F, Hayden MK, Jernigan JA, Weinstein RA, Fraser VJ, Haffenreffer K, Cui E, Kaganov RE, Lolans K, Perlin $J$ B, Platt R, Program CDCPE, Network AD, Healthcare-Associated Infections P (2013) Targeted versus universal decolonization to prevent ICU infection. N Engl J Med 368:2255-2265

10. Milstone AM, Elward A, Song X, Zerr DM, Orscheln R, Speck K, Obeng D, Reich NG, Coffin SE, Perl TM, Pediatric STSG (2013) Daily chlorhexidine bathing to reduce bacteraemia in critically ill children: a multicentre, cluster-randomised, crossover trial. Lancet 381:1099-1106

11. Noto MJ, Domenico HJ, Byrne DW, Talbot T, Rice TW, Bernard GR, Wheeler AP (2015) Chlorhexidine bathing and health care-associated infections: a randomized clinical trial. JAMA 313:369-378

12. Adrie C, Garrouste-Orgeas M, Ibn Essaied W, Schwebel C, Darmon M, Mourvillier B, Ruckly S, Dumenil AS, Kallel H, Argaud L, Marcotte G, Barbier F, Laurent V, Goldgran-Toledano D, Clec'h C, Azoulay E, Souweine B, Timsit JF, Group* OS (2017) Attributable mortality of ICU-acquired bloodstream infections: impact of the source, causative micro-organism, resistance profile and antimicrobial therapy. J Infect 74:131-141

13. La Combe B, Bleibtreu A, Messika J, Fernandes R, Clermont O, Branger C, Billard-Pomares T, Barnaud G, Magdoud F, Eveillard M, Kouatchet A, Lasocki S, Asfar P, Corvec S, Lakhal K, Armand-Lefevre L, Wolff M, Timsit JF, Bourdon S, Reignier J, Martin S, Fihman V, de Prost N, Bador J, Charles PE, Goret J, Boyer A, Wallet F, Jaillette E, Nseir S, Landraud L, Ruimy R, Danin PE, Dellamonica J, Cremniter J, Frat JP, Jaureguy F, Clec'h C, Decre D, Maury E, Dreyfuss D, Denamur E, Ricard JD (2018) Decreased susceptibility to chlorhexidine affects a quarter of Escherichia coli isolates responsible for pneumonia in ICU patients. Intensive Care Med 44:531-533

14. Marolf CT, Alter R, Lyden E, Fey PD, Rupp ME (2017) Susceptibility of nosocomial staphylococcus aureus to chlorhexidine after implementation of a hospital-wide antiseptic bathing regimen. Infect Control Hosp Epidemiol 38:873-875

15. Deeren D, Dewulf E, Verfaillie $L$ (2016) Daily chlorhexidine bathing does not increase skin toxicity after remission induction or stem cell transplantation. Acta Clin Belg 71:379-382 